\title{
Avaliação do risco da alocação de água em período de escassez hídrica: o caso do Sistema Jaguaribe-Metropolitano
}

\author{
Risk assessment of water allocation on water \\ scarcity period: the case of Jaguaribe-Metropolitan System
}

Samiria Maria Oliveira da Silva', Francisco de Assis Souza Filho², Sandra Helena Silva Aquino

口-

\section{RESUMO}

O artigo avalia a transferência de risco de uma politica de alocação de água entre dois setores usuários: abastecimento urbano e irrigação. Para isso, a alocação entre usos foi realizada utilizando dois métodos: rateio linear e rateio com prioridades (adotado em períodos de escassez hídrica). O volume disponível para alocação foi obtido utilizando duas estratégias de operação de reservatórios: vazão afluente zero no segundo semestre do ano e previsão de vazão. Os ganhos e perdas dos setores usuários foram determinados por meio de funções benefícios. Os dois cenários de alocação apontaram garantias e benefícios menores para setor usuário de menor prioridade. O sistema de prioridade revelou que as infraestruturas de transferências hídricas proporcionam ganhos ao garantir a segurança hídrica para o setor prioritário, porém causam perdas quando extinguem o direito de uso da demanda de menor prioridade, indicando que a alocação de água também é um processo de distribuição de risco. A transferência de risco desse setor, tanto volumétrica quanto monetária, pode ser minimizada com o uso da informação climática. Uma alternativa para a alocação deágua emambientes com sistema de transferência hídrica seria definir um risco aceitável com vistas a aumentar o nível atual de benefícios da irrigação e a satisfação do abastecimento urbano. Esse risco pode ser estabelecido com base em modelos de previsão climática sazonal.

Palavras-chave: transferência hídrica; realocação de água; rateio com prioridade e rateio linear.

\begin{abstract}
The article evaluates the transfer of risk of a water allocation policy between two user sectors: urban supply and irrigation. The allocation between uses was performed using two methods: linear apportionment and assessment with priorities (adopted in periods of water scarcity). The amount available for allocation was obtained using two reservoir operation strategies: zero inflow in the second half of the year and forecast flow. Gains and losses of the user sectors were determined through benefits functions. The two allocation scenarios pointed to lower guarantees and benefits for user sector with less priority. The priority system revealed that the water transfer infrastructures provide gains for the higher priority sector when guaranteeing water security; however, cause losses when extinguishes the right to use the demand of lower priority, indicating that the allocation of water is also a distribution process risk. The transfer risk of this sector, volumetric and monetary, can be minimized with the use of climate information. Thus, an alternative to the allocation of water in environments with water transfer systems would be an acceptable risk in order to increase the current level of benefits of irrigation and the satisfaction of the urban supply. This risk can be established based on seasonal climate prediction models.
\end{abstract}

Keywords: water transfers; water reallocation; apportionment priority and apportionment linear.

\section{INTRODUÇÃO}

A história da apropriação do recurso água pelas diversas sociedades é marcada por crises de ordens econômicas, sociais, políticas, por inovações tecnocientíficas e pela compreensão do tempo-espaço.
Para Harvey (2014), o tempo instantâneo e o espaço fluido se constroem e se reconstroem por relações sociais que extrapolam os limites fronteiriços dos lugares e modificam as relações próximo-distante e local-local.

\section{口}

'Doutora em Recursos Hídricos. Professora Adjunta do Curso de Engenharia Civil da Universidade Federal do Ceará (UFC) - Campus de Russas - Russas (CE), Brasil. ${ }^{2}$ Doutor em Engenharia Civil. Professor Adjunto do Departamento de Engenharia Sanitária e Ambiental da UFC - Fortaleza (CE), Brasil.

${ }^{3}$ Mestre em Meio Ambiente e Desenvolvimento. Pesquisadora do Grupo de Gerenciamento de Risco Climático e Sustentabilidade Hídrica. Doutoranda em Sociologia na UFC Fortaleza (CE), Brasil.

Endereço para correspondência: Samiria Maria Oliveira da Silva - Rua Felipe Santiago, 411 - Cidade Universitária - 62900-000 - Secretaria do Campus de Russas, Russas (CE), Brasil - E-mail:samiriamaria@hotmail.com

Recebido: 18/03/16 - Aceito: 11/08/16 - Reg. ABES: 161303 
Os limites do tempo foram ultrapassados por meio dos reservatórios que transportam água entre estações e/ou entre anos. $\mathrm{O}$ espaço, desconstruído ou conectado por meio das grandes infraestruturas de transferência de água como, por exemplo, a adutora Tajo-Segura na Espanha, o sistema de Wanjiazhai na China e, no Brasil, o sistema Cantareira construído para transferir água dos rios formadores do rio Piracicaba para a bacia do Alto Tietê para abastecer a Região Metropolitana de São Paulo, o Eixão das Águas e o Canal do trabalhador implementados para transpor água da bacia do Jaguaribe para a Região Metropolitana de Fortaleza (RMF) no Estado do Ceará e o canal Redenção utilizado para interligar os reservatórios Coremas e Mãe D’água.

As novas conexões de tempo-espaço advindas desses sistemas revelam a necessidade de repensar a política de gestão de recursos hídricos e, mais especificamente, as regras e os mecanismos de alocação de água entre os múltiplos usuários, uma vez que os acontecimentos em nível local não são mais determinados apenas por fatores que se originam no próprio lugar.

Os sistemas de transferência de água dentro de uma bacia ou entre bacias são uma forma de solucionar o deficit hídrico e tornam o processo de gestão da água complexo em virtude das diferentes realidades socioeconômicas e ambientais, bem como das distintas considerações políticas. Esses sistemas podem ainda implicar, positivamente ou negativamente, impactos sociais, culturais e econômicos aos usuários das bacias doadoras e receptoras e que se localizam ao longo do traçado do caminho que ligará as duas bacias, a depender das metas a serem alcançadas e das alternativas escolhidas (BANCO MUNDIAL, 2005).

As regras e os mecanismos de alocação, nesse contexto, são aspectos chave para o alcance da sustentabilidade hídrica e para uma distribuição de água equitativa e eficiente. Eles precisam ser flexíveis, robustos e não mais definidos com base em metodologias calcadas em alguma racionalidade para que as resoluções atendam da melhor forma possível às expectativas de alguns segmentos da sociedade (MACHADO, 2009).

Desse modo, este artigo se propõe a avaliar o risco de uma política de alocação de água entre usos localizados em bacias hidrográficas distintas, mas conectados pelas infraestruturas de transferência hídrica. Essa política está pautada na priorização de um uso em detrimento do outro no período de escassez hídrica. O risco será visualizado pelas oportunidades e pelos perigos, isto é, pelos ganhos da possibilidade de redução dos efeitos da variabilidade hidrológica para um determinado setor usuário e pelas perdas relacionadas com o risco de falha no atendimento da demanda de outro usuário. Essa avaliação tem base em duas hipóteses de operação e reservatórios: vazão afluente zero e previsão de vazão.

\section{ALOCAÇÃO DE ÁGUA}

A alocação de água configura-se como uma tomada de decisão no gerenciamento de recursos hídricos e se refere às regras e aos procedimentos por meio dos quais é decidida se a distribuição da água é para uso individual ou coletivo, em relação à sua disponibilidade (ROA-GARCÍA, 2014). É um processo que tende a ser marcado por conflitos em virtude da escassez do próprio recurso (em termos de quantidade, qualidade, tempo de disponibilidade ou confiabilidade), que gera, muitas vezes, o desequilíbrio entre a oferta e a demanda.

A análise sistêmica da alocação envolve significativa análise econômica, social, ambiental e avaliação de compensação entre usos competitivos. Assim, conforme Speed et al. (2013), um moderno processo de alocação de água é um exercício socioeconômico com base na hidrologia e na engenharia. Esse exercício é realizado para cumprir alguns objetivos globais que podem ou não estar explícitos na legislação. Esses objetivos, que giram em torno dos pilares do desenvolvimento sustentável (LAYRARGUES, 1997), são: equidade, eficiência econômica e sustentabilidade.

A eficiência econômica, nesse contexto, explora todas as possibilidades de ganhos entre agentes sociais e econômicos por intermédio de trocas de bens e serviços. Uma alocação economicamente eficiente da água é desejável na medida em que maximiza o bem-estar que a sociedade obtém dos recursos hídricos disponíveis. Essa situação refere-se ao bem-estar econômico da sociedade e é determinado pelo bem-estar agregado dos usuários de água (FAO, 2004).

A equidade trata como a riqueza é distribuída na sociedade ou, mais especificamente, como se dá uma alocação justa entre os diferenciados setores usuários. A justiça distributiva para recursos prioritários, como a água, mostra que as sociedades priorizam alguns critérios de consideração da justiça, tais como a maximização da utilidade e a distribuição igualitária. Esses critérios foram desenvolvidos na teoria da justiça utilitarista de Jeremy Bentham (1789) e na teoria da justiça de John Rawls (1971 e 2002).

O termo sustentabilidade, como adjetivo do desenvolvimento, surgiu em face da percepção de uma crise ambiental global causada pelo incessante padrão de crescimento da produção e do consumo nos países ricos (NASCIMENTO, 2012). Em recursos hídricos, o alcance da sustentabilidade exige que a água seja usada e alocada de forma que os sistemas hídricos se mantenham dentro de sua capacidade de regeneração, a fim de manter os ecossistemas e suas funções. Para isso, faz-se necessária a adoção de estratégias que tenham em vista a garantia de atendimento das necessidades das gerações presentes, sem comprometer as das gerações futuras. 


\section{LOCAL DE APLICAÇÃO}

O estudo foi baseado no sistema Jaguaribe-Metropolitano situado no semiárido do Brasil, Estado do Ceará (Figura 1). Esse sistema foi escolhido por ser considerado o principal sistema de reservatórios desse Estado. Possui uma vazão anual altamente variável, elevadas taxas de evaporação dos lagos, está submetido à variabilidade temporal das precipitações e situado em solos rasos com predominância de rochas cristalinas.

O sistema Jaguaribe-Metropolitano surge com a construção do canal do trabalhador e se estabelece com a implementação do eixo de integração da bacia do rio Jaguaribe com a RMF, conhecido como Eixão das Águas.

A bacia do rio Jaguaribe compreende aproximadamente $48 \%$ do Estado do Ceará, com uma área de $72 \mathrm{mil} \mathrm{km²}$. Devido a sua extensão e para facilitar o processo de gestão, ela foi dividida em cinco sub-bacias, são elas: Alto Jaguaribe, Banabuiú, Médio Jaguaribe, Salgado e Baixo Jaguaribe.

O principal usuário de água dessa bacia é a irrigação que representa cerca de $90 \%$ da produção agrícola da bacia com ênfase na fruticultura irrigada. Ela tem como principais reservatórios o Orós, o Banabuiú e o Castanhão, que somam uma capacidade de acumulação de $10.241,00 \mathrm{hm}^{3}$. O primeiro pereniza um trecho de 109,24 km;

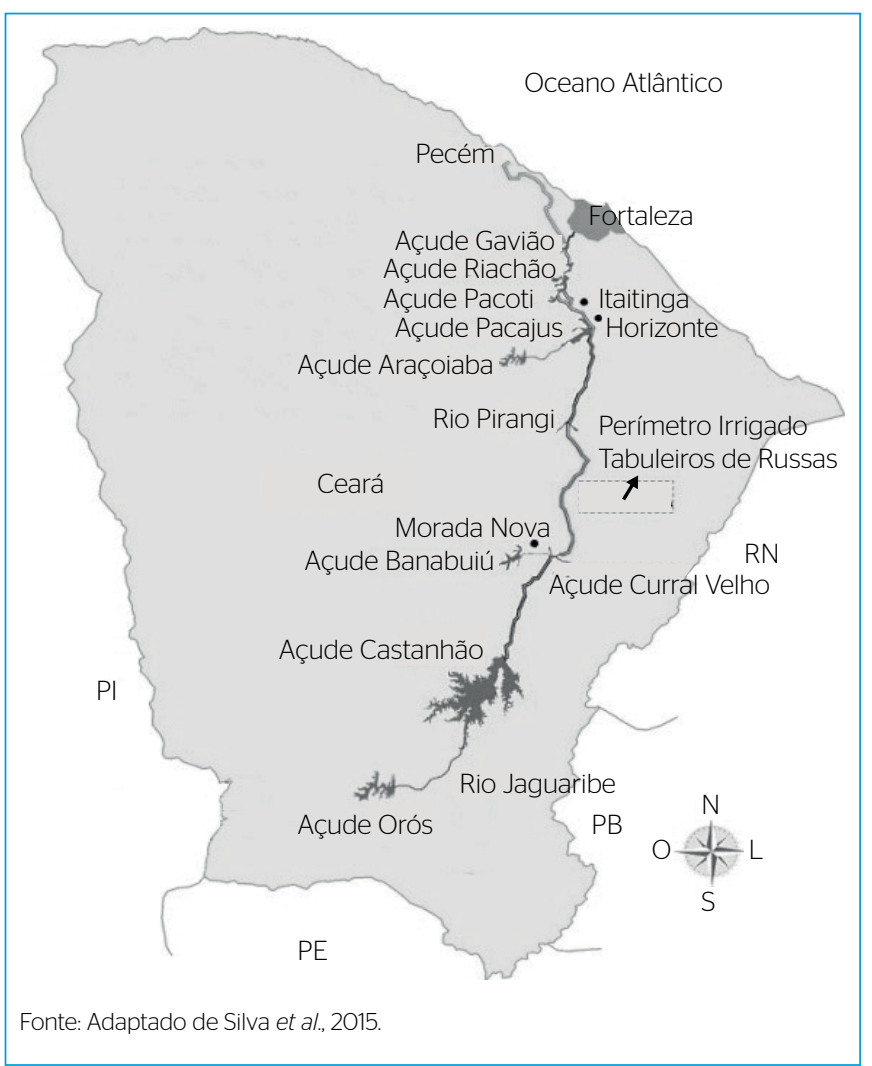

Figura 1 - Localização do Sistema Jaguaribe-Metropolitano no Estado do Ceará, Nordeste do Brasil. o açude Banabuiú pereniza um trecho de 135,90 km; e o Castanhão, um trecho de $150,34 \mathrm{~km}$.

O sistema de abastecimento da RMF é composto por cinco reservatórios que somam uma capacidade de acumulação de $871 \mathrm{hm}^{3}$, são eles: Gavião, Pacoti e Riachão, Pacajus e Araçoiaba, sendo esses reservatórios interligados por canais e adutoras. No entanto, devido às políticas de industrialização do Estado, a demanda industrial da RMF aumentou substancialmente (COGERH, 2010) e essa região passou a ter seu abastecimento realizado com águas provenientes da transposição de bacias.

A demanda hídrica da RMF é composta pelo abastecimento humano, indústria, serviços e turismo. Na porção oeste dessa região situa-se o Complexo Industrial Porto do Pecém (CIPP), com empresas ligadas ao setor energético. Esse complexo é visualizado pelo Estado como uma importante estratégia de desenvolvimento econômico regional e recebe um número crescente de investimentos governamentais.

\section{METODOLOGIA}

Para desenvolver este estudo, inicialmente foram obtidas as disponibilidades hídricas (vazão de retirada) para cada ano da série histórica, utilizando a operação do reservatório com vazão afluente zero e previsão de vazão. Em seguida, a vazão de retirada foi alocada para os usuários utilizando dois modelos de alocação: rateio linear e rateio com prioridades. Com os valores das vazões atendidas em cada setor, foram determinados os benefícios financeiros e os riscos da regra de alocação de água.

\section{Situação de aplicação}

Para realizar as análises, o reservatório Orós foi considerado como único reservatório da bacia do Jaguaribe e sua vazão máxima alocável foi distribuída entre dois usuários: a irrigação (principal setor usuário da bacia do Jaguaribe) e o abastecimento urbano (representando a demanda da RMF). O primeiro é composto pelos usuários da irrigação que buscam garantir seu lucro pelo uso da água no presente. O abastecimento urbano é representado pelos usuários urbanos (famílias, indústrias, comércio, serviços e turismo), que buscam garantir o acesso à água, colocando-se como uma demanda prioritária, isto é, aquela para a qual será dada preferência para o uso da água no período de escassez.

O reservatório Orós possui uma capacidade máxima de armazenamento de $1.940 \mathrm{hm}^{3}$. De acordo com a Lei de Recursos Hídricos do Estado do Ceará (Lei $\mathrm{n}^{\circ} 14.844 / 2010$ ), a água disponível para distribuição é de $90 \%$ do volume $\mathrm{Q}_{90}$. Com isso, admitiu-se que a demanda urbana correspondeu a $30 \%$ da demanda total e ao setor de irrigação aplicou-se $70 \%$ da demanda total. 


\section{Determinação da disponibilidade hídrica e alocação entre usos}

A operação do reservatório é o primeiro passo da alocação da água estocada. Ela tem por objetivo definir a vazão a ser liberada para atender a uma demanda, em função do estado atual do reservatório. A vazão disponível para a alocação entre o abastecimento urbano e a irrigação foi determinada utilizando duas estratégias de operação do reservatório: vazão zero (estratégia adotada na alocação de água do Estado do Ceará) e previsão de vazão.

No cenário de vazão zero, o sistema hídrico é simulado com vazões afluentes zero (estado mais crítico para o sistema) no período de julho a dezembro (futuro conhecido de seis meses). Essa hipótese é aplicada para o período de escassez hídrica devido ao comportamento de aversão ao risco do decisor e os menores benefícios estarem associados a ela.

A tomada de decisão da alocação foi realizada em julho, uma vez que, no semiárido, o ano tem dois ciclos: o primeiro semestre, quando há a possibilidade de ocorrência de vazões significativas; e o segundo semestre, em que os rios apresentam vazão zero. Assim, a disponibilidade de água superficial é única e exclusivamente da água oriunda dos reservatórios, o que implica que conhecer os estoques de água em julho é conhecer a disponibilidade hídrica superficial dessa região, nesse segundo semestre.

Para atender à necessidade de regularização plurianual, manteve-se no reservatório a quantidade de água que satisfizesse as demandas humanas no ano seguinte, sem racionamento. A simulação foi realizada ao longo dos 18 meses seguintes à tomada de decisão, seguindo o balanço hídrico descrito na Equação 1 .

$V_{t+1}=V_{t}+I_{t}-E_{t}^{*} A-R_{t}-S_{t}$

Em que:

I é a afluência;

$E$ é a evaporação;

$A$ é a área do espelho d'água;

$S$ é o vertimento (retirada de água não controlada);

$t$ é o mês; e

$R_{t}$ representa a retirada controlada.

As variáveis de fluxo do reservatório são o armazenamento $(\mathrm{V})$ e a afluência (I). A variável de decisão é a retirada, $\mathrm{R}_{t,}$, que está condicionada por uma retirada máxima, $\mathrm{R}_{\max }$ (Equação 2).

$R \leq R_{\max }$

Foram utilizados os dados de evaporação disponíveis no banco de dados das normas climatológicas do Instituto Nacional de
Meteorologia (INMET), considerando a cidade de Iguatu. Esses dados foram observados em evaporímetros de piche, com distribuição mensal considerando o período de 1961 a 1990. Para representar a evaporação sobre o reservatório, adotou-se $80 \%$ dos valores da variável evaporação média.

A previsão de vazão tem por objetivo reduzir o erro da utilização da série histórica tanto na estimativa do valor esperado como na redução da dispersão das vazões utilizadas para a construção de um cenário de alocação (SOUZA FILHO, 2005). Nesse cenário, as vazões afluentes em cada ano foram definidas por meio do modelo de previsão climática de vazão desenvolvida por Souza Filho e Lall (2003; 2004)

O modelo de previsão climática utiliza metodologia estatística semiparamétrica. Indicadores do estado climático, tais como a temperatura da superfície do mar do oceano Pacífico (região do El Niño) e do Atlântico (região intertropical), são utilizados para prever as vazões afluentes a reservatórios do nordeste setentrional brasileiro.

A simulação é realizada para um período de 24 meses, com início em julho. Nesse mês, faz-se a previsão de vazões do período úmido do ano seguinte (janeiro a junho), uma vez que o rio é intermitente e suas vazões são zero no período de julho a dezembro. Em janeiro, é emitida uma nova previsão e as decisões de liberação do reservatório podem ser atualizadas. Com isso, na tomada de decisão da vazão regularizada do reservatório, pode-se utilizar essa previsão em combinação com os níveis de água atuais do reservatório.

A operação com a informação climática possibilitou também a avaliação do risco na alocação de água. Para isso, avaliou-se como se daria a alocação caso o tomador de decisão aceitasse um risco de falha de 5 e $25 \%$ para o abastecimento urbano.

A vazão anual alocável para o sistema foi distribuída entre os dois setores usuários por meio de dois modelos de alocação, são eles: rateio linear e sistema de prioridades. Esses métodos se baseiam na alocação realizada no Estado do Ceará, onde em período de escassez hídrica adota-se um sistema de prioridade e quando não ocorre essa carência todos os usuários recebem água com a mesma garantia hídrica.

O rateio linear foi utilizado como método base, pois ele permite que os usuários tenham as mesmas garantias hídricas e assim não ocorra transferência de risco. Nesse método, a disponibilidade hídrica foi distribuída linearmente entre os usuários conforme as Equações 3 e 4.

$Q_{i, t}=0,70 * R_{t}$

$Q_{u, t}=0,30 * R_{t}$ 
Em que:

$Q_{i, t}$ é a vazão alocável do setor de irrigação no tempo t;

$Q_{u, t}$ é a vazão alocável do abastecimento urbano no tempo t;

$R_{t}$ é a retirada controlada do sistema, obtida após a operação do reservatório $\mathrm{em} \mathrm{hm}^{3}$. $\mathrm{nno}^{-1}$.

O método de prioridades caracteriza-se pela escolha prioritária de um setor em detrimento de outros, de um segundo setor em prejuízo dos restantes, e assim por diante. Nesse caso, leva-se em consideração a Lei Estadual de Recursos Hídricos, que expressa o seguinte como fundamento: “(...) em situações de escassez, o uso prioritário dos recursos hídricos é o consumo humano e a dessedentação de animais". Dessa forma, a prioridade legal é do setor urbano em detrimento da irrigação em épocas de escassez.

Para esse método, tem-se as seguintes condições (Equações 5 e 6):

$Q_{u, t}=\begin{aligned} & R_{t}, \text { se } R t<D u \\ & D u, \text { se } R t \geq D u\end{aligned}$

$Q_{i, t}=$ mínimo $\left(R_{t}-D_{u} ; D_{i}\right)$

Em que:

$Q_{u, t}$ é a vazão urbana atendida no tempo t, $\mathrm{em} \mathrm{hm}^{3}$.ano ${ }^{-1}$;

$Q_{i, t}$ corresponde à vazão atendida do setor de irrigação no tempo t, em hm hano $^{-1}$;

$R_{t}$ é a vazão de retirada do sistema no tempo t obtida na operação do reservatório, em $\mathrm{hm}^{3}$.ano ${ }^{-1}$;

$D_{u}$ simboliza a demanda urbana em $\mathrm{hm}^{3}$.ano ${ }^{-1}$;

$D_{i}$ é a demanda da irrigação $\mathrm{em} \mathrm{hm}^{3} \cdot \mathrm{ano}^{-1}$.

A alocação entre usos foi avaliada quanto aos seguintes critérios de desempenho:

1. Rendimento médio do setor usuário $\left(\mathrm{hm}^{3} \cdot \mathrm{ano}^{-1}\right)$ - Corresponde ao volume médio alocado para cada setor usuário de água (Equação 7):

$\operatorname{Re} n d=\frac{1}{n} \sum_{i=1}^{n} Q_{i}$

2. Garantia percentual - É o percentual de tempo em que a demanda foi atendida (Equações 8 e 9).

$G_{r}=1-P_{r}$

$P_{r}=\frac{n_{r}}{n}$

Em que:

$n_{r}$ é a demanda total, segundo a regra operacional adotada; $\mathrm{e}$ $n$ é o número total de anos da simulação.
3. Garantia volumétrica - É a razão entre volume ofertado e volume demandado. Ela foi calculada pela Equação 10.

$G_{v}=1-P_{v}$

Em que:

$P_{v}$ corresponde ao volume percentual da demanda que não pôde ser abastecida durante todo o período de simulação.

\section{Avaliação dos riscos na alocação de água}

Os ganhos e as perdas dos usuários foram avaliados por meio da diferença dos benefícios alcançados por cada setor nos dois métodos de rateio das disponibilidades hídricas, conforme apresentado na Equação 11:

$T R=\Delta B_{u}-\Delta B_{i}$

Em que:

$\Delta B_{u}$ é a diferença de benefícios entre os dois métodos de rateio de disponibilidade hídrica pelo setor urbano;

$\Delta B_{i}$ representa a diferença de benefícios entre os dois métodos de rateio de disponibilidade hídrica pelo setor de irrigação; e

TR é o risco transferido entre os usuários, isto é, os ganhos de um setor e as perdas do outro.

A diferença de benefício foi calculada pela Equação 12:

$\Delta B=B_{k}^{R L}-B_{k}^{P R}$

Em que:

$B_{k}^{R L}$ é o benefício financeiro obtido pelo setor usuário $k$ utilizando o método do rateio linear (RL) na alocação de água; e

$B_{k}^{R L}$ corresponde ao benefício financeiro obtido pelo setor usuário $k$ com o método de alocação com prioridades (PR).

Para esse estudo, os benefícios foram calculados utilizando as funções (Equações 13 e 14) propostas por Souza Filho e Brown (2009), que foram geradas a partir da integração das curvas de demanda do abastecimento urbano e da irrigação. Contudo, as análises desse estudo podem ser realizadas utilizando outras funções benefício.

$B_{i, t}=\frac{-0,137 * Q_{i, t}{ }^{2}+79,51 * Q_{i, t}}{1000}$

$B_{u, t}=\left(-4,75 *\left(\frac{Q_{u, t}}{12}\right)^{-0,818}+2,17\right) * 12$

Em que: 
$B_{i, t}$ é a função benefício da irrigação em milhões de reais no ano $t$;

$B_{u, t}$ simboliza a função benefício do abastecimento urbano em milhões de reais;

$Q_{i, t}$ corresponde à vazão atendida da irrigação, em $\mathrm{hm}^{3}$.ano ${ }^{-1} ; \mathrm{e}$

$Q_{u, t}$ representa a vazão atendida do setor de abastecimento urbano, em $\mathrm{hm}^{3}$.ano ${ }^{-1}$.

\section{RESULTADOS E DISCUSSÃO}

As afluências históricas ao reservatório Orós se concentram no período de janeiro a julho, com vazão zero a partir do mês seguinte (Figura 2). Elas apresentam uma pronunciada variabilidade interanual com média histórica de $34,70 \mathrm{~m}^{3} \cdot \mathrm{s}^{-1}$ e coeficiente de variação de $1,28 \mathrm{~m}^{3} \cdot \mathrm{s}^{-1}$ (Figura 3 ), considerando o período de 1912 a 1996.

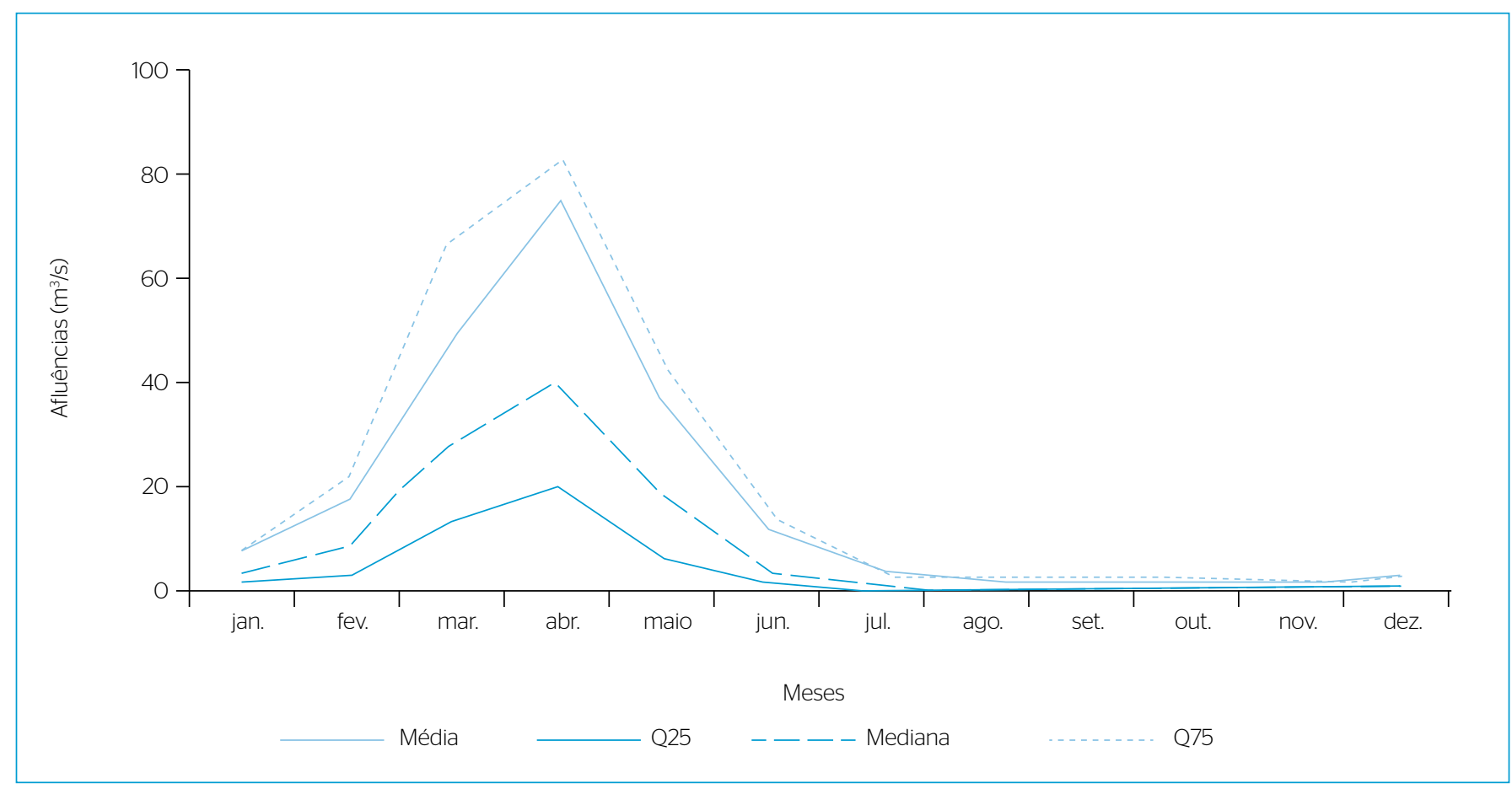

Figura 2 - Variação sazonal das afluências ao reservatório Orós, representada pelos valores mensais da média, mediana e quantis de $25 \%$ e $75 \%$, considerando o período de 1912 a 1996.

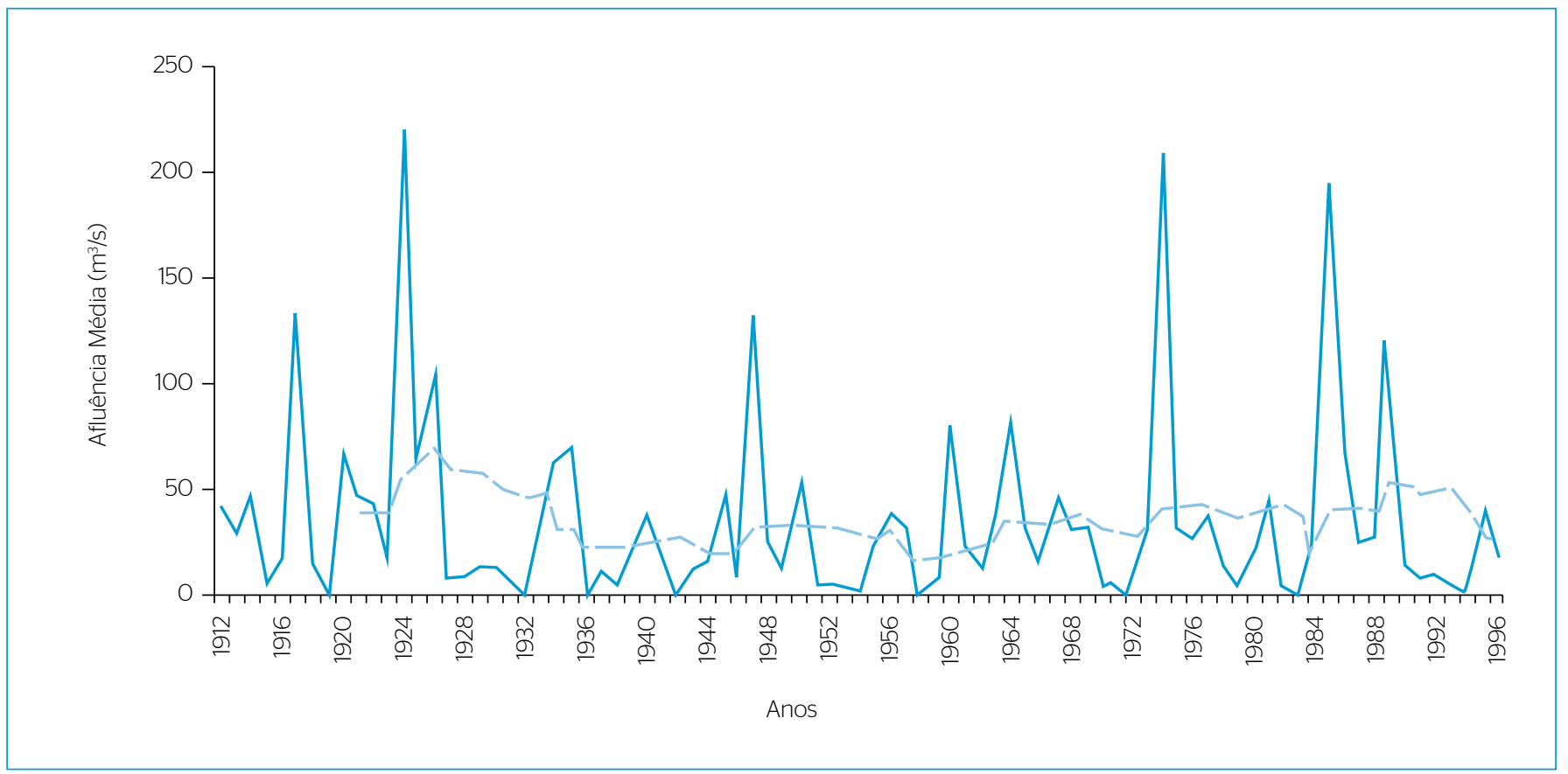

Figura 3 - Vazão média anual afluente do reservatório Orós (1912-1996) em linha contínua e média móvel de 10 anos em linha tracejada. 
Também pode ser observada, nessa série, a variação decadal com um valor máximo de $70,84 \mathrm{~m}^{3} \cdot \mathrm{s}^{-1}$, no período de 1917 a 1926, e mínimo de $17,00 \mathrm{~m}^{3} \cdot \mathrm{s}^{-1}$, na década de 1950 a 1959 . Essa variabilidade pode estar associada a uma maior severidade dos eventos de seca e cheia. Ela impacta o volume alocável de longo prazo do reservatório. Esse volume é uma função da garantia do suprimento desejada. Maiores garantias estão associadas a volumes menores. A garantia ótima pode ser diferente para distintos usos e usuários.

O volume alocável (outorgável) de longo prazo no Ceará é $90 \%$ da vazão com $90 \%$ de garantia. Isso pode não assegurar o ponto ótimo de utilização para os diferentes usos e usuários. Observa-se também que há diferença entre os valores de vazão obtidos ao calcular a garantia de forma anual, mensal ou a garantia volumétrica (razão entre volume ofertado e volume demandado). A Lei de Águas do Ceará não especifica a qual dessas garantias se refere (CEARÁ, 2010).

Todos os usos são outorgados com a garantia de $90 \%$ calculado como sendo em média uma falha no abastecimento a cada 10 anos. Verificou-se que esse volume para o Orós corresponde a $600 \mathrm{hm}^{3}$. $a^{-1}$. Essa vazão é usada como referência para legislação na área de Meio Ambiente e de Recursos Hídricos e está associada à incerteza do suprimento hídrico produzida pela grande variabilidade dos deflúvios. Assim, ela impõe riscos operacionais ao hidrossistema, o que ressalta a necessidade de aplicar a gestão de risco em recursos hídricos, de adaptar as regras, os instrumentos e as instituições que governam a relação entre os agentes socioeconômicos.

O resultado da alocação entre usos, utilizando o método de rateio linear e sistema de prioridade para a estratégia de vazão zero, está representado na Figura 4. Na alocação com rateio linear, nenhum dos setores foi submetido ao colapso durante o período estudado enquanto, no sistema de prioridades, a irrigação é submetida a maiores falhas apresentando 10 anos da série histórica em que a oferta de água foi completamente cessada a fim de fornecê-la para o abastecimento urbano. Nesse caso, um grande deficit na oferta de água para o setor supracitado levaria a um custo social e econômico muito alto, por isso é necessário reduzir ou mitigar esse risco, o que pode ser realizado com o uso de instrumentos econômicos e financeiros.

Utilizando a previsão climática com risco de $5 \%$ e alocação por prioridade, a irrigação esteve em colapso na mesma frequência de ocorrência do cenário de vazão zero, enquanto com o risco de $25 \%$ esse setor foi submetido ao colapso em apenas cinco anos (Figura 5).

Além disso, no cenário de vazão zero e alocação por prioridade, o rendimento médio do sistema foi de $494,20 \mathrm{hm}^{3}$.ano ${ }^{-1}$. Com a utilização da previsão climática, esse rendimento aumentou em $8,61 \mathrm{hm}^{3}$. ano $^{-1}$ (previsão com risco $=5 \%$ ) e $40,52 \mathrm{hm}^{3}$.ano ${ }^{-1}$ (previsão com risco $=25 \%$ ), ou seja, mais água foi entregue ao sistema.
Nesse contexto, Guihan (2013) ressalta que, ao visualizar os dados de previsão climática por meio da lente da gestão das águas como uma ferramenta de apoio à decisão, é possível compreender melhor como os sistemas climáticos impactam os recursos hídricos e alcançar uma maior eficiência nessa resolução pelos gestores. Robertson et al. (2014) dizem que a previsão climática é um instrumento importante para subsidiar as decisões de alocação de água em regiões semiáridas. Gong et al. (2010) expõem que essa ferramenta permite que os gestores tomem decisões pró-ativas, em vez de decisões reativas com base em hipóteses de condições críticas na operação de reservatórios.

O desempenho da alocação de água para o setor de abastecimento humano e irrigação pode ser visualizado nas Tabelas 1 e 2 . Observou-se que a operação do reservatório com vazão zero e a imposição de racionamento a alguns usos antes do reservatório entrar em colapso, em curto prazo, podem ser eficientes, porém, em longo prazo, gera garantias diferenciadas entre os diversos usuários, podendo aumentar significativamente as garantias do abastecimento urbano com relação à garantia realizada no cálculo da outorga e reduzindo drasticamente as garantias para os outros usos. Assim, a utilização da previsão de vazões na operação de reservatórios pode ser uma ferramenta para avaliar o risco existente na próxima temporada da alocação de água e, assim, melhorar a utilização dos recursos hídricos disponíveis.

Analisando as funções benefícios de Souza Filho e Brown (2009), utilizadas nesse estudo, percebe-se que, a partir de $293 \mathrm{hm}^{3} . \mathrm{ano}^{-1}$, o setor de irrigação começa a ter o benefício marginal negativo, ou seja, os benefícios diminuem com o aumento da vazão e até $31 \mathrm{hm}^{3}$.ano ${ }^{-1}$, o setor urbano possui benefício negativo. Por isso, considera-se benefício zero para vazões até $31 \mathrm{hm}^{3}$.ano-1 para o setor urbano; e o benefício máximo para vazões acima de $293 \mathrm{hm}^{3}$.ano ${ }^{-1}$.

A variação do benefício total, tanto pelo sistema de prioridade quanto pelo método de rateio, é quase totalmente absorvida pelo setor de irrigação. O setor urbano obteve benefício médio anual de $\mathrm{R} \$ 17,27$ milhões e $\mathrm{R} \$ 19,52$ milhões para o rateio linear e o sistema de prioridade, respectivamente, enquanto a irrigação alcançou um valor médio de $\mathrm{R} \$ 9,29$ milhões com o rateio linear e $\mathrm{R} \$ 8,22$ milhões no sistema de prioridade (Tabela 3). Utilizando a informação climática, a irrigação teve um crescimento dos benefícios médios tanto no rateio linear quanto no sistema de prioridade. Já o abastecimento urbano teve um decréscimo do benefício médio quando foi usado o risco de 5\% (Tabela3).

A variação dos benefícios mostra a transferência de risco ocorrida entre dois setores. Nesse caso, verificou-se que a irrigação perdeu $\mathrm{R} \$ 1,06$ milhões e o abastecimento urbano ganhou R \$2,30 milhões no cenário de vazão zero. Esses valores são explicados pela transferência volumétrica realizada do setor de irrigação para o setor prioritário, 
com média de 25,42 $\mathrm{hm}^{3}$.ano ${ }^{-1}$. Em termos monetários, essa transferência média representa $\mathrm{R} \$ 3,36$ milhões (Tabela 4). Verificou-se que a transferência de risco, tanto a volumétrica quanto a monetária, pode ser minimizada com o uso da informação climática.

Em suma, os dois cenários de alocação mostram garantias e benefícios menores para a irrigação e deficiências menos frequentes para o setor urbano quando se utiliza o sistema de prioridade; isto é, durante os períodos de escassez, a prioridade de uso definido da Lei impõe um risco ao usuário de menor prioridade.
Ressalta-se que o planejamento de longo prazo dos recursos hídricos do Estado do Ceará é baseado na estacionariedade das séries temporais. Assim, todos os usuários são outorgados com 90\% de garantia e esse direito se modifica em período de escassez hídrica, tendo água apenas os usuários com maior prioridade. Essa é uma situação de iniquidade em longo prazo e uma incompatibilidade entre os mecanismos de alocação, uma vez que existe uma discrepância entre as garantias outorgadas e as garantias efetivas dos sistemas hídricos.

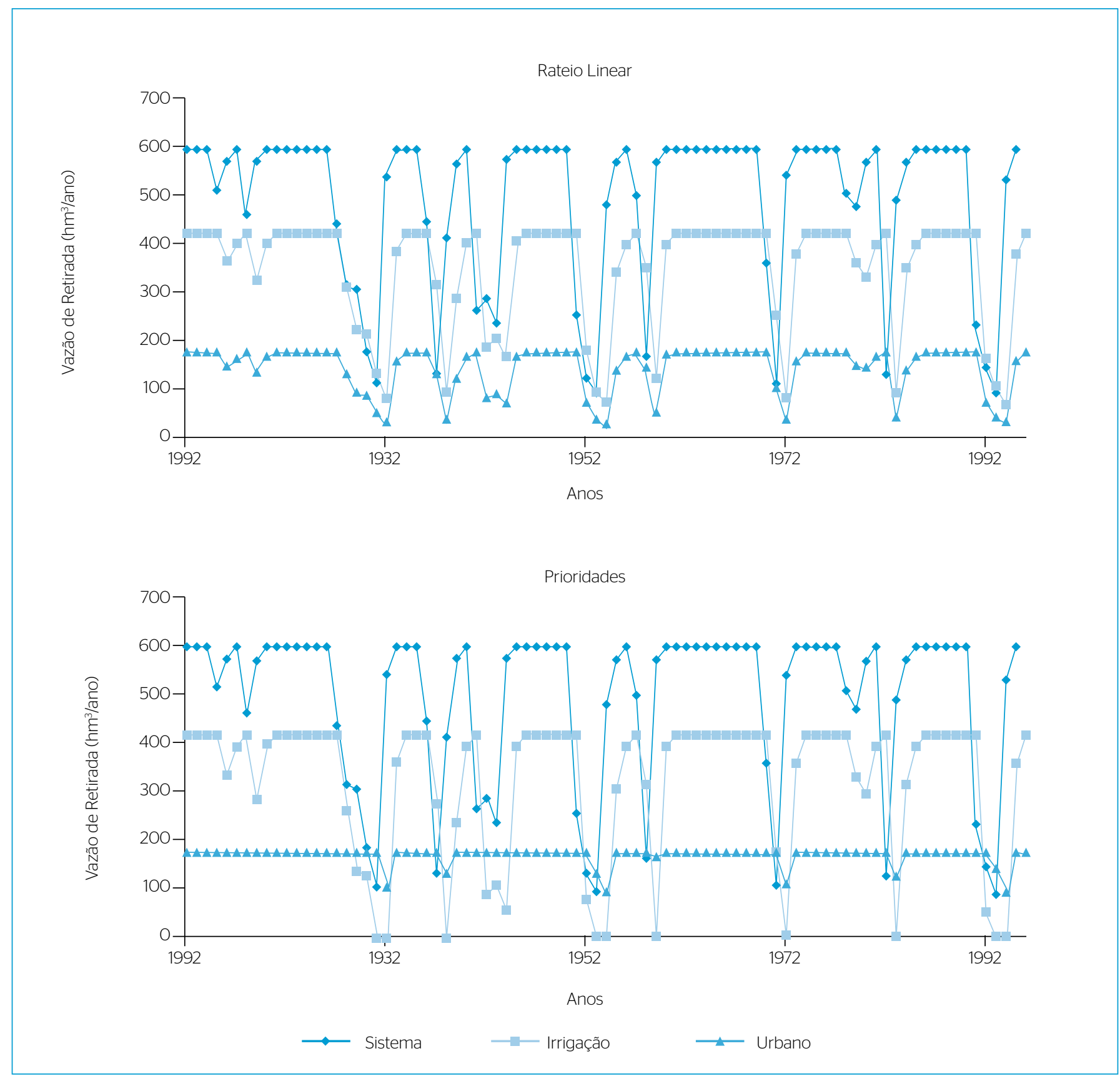

Figura 4 - Vazão alocada com o mecanismo de prioridade e rateio linear ( $\mathrm{hm}^{3}$.ano-1) no cenário de vazão zero, utilizando a série histórica de julho de 1912 a julho de 1996. 


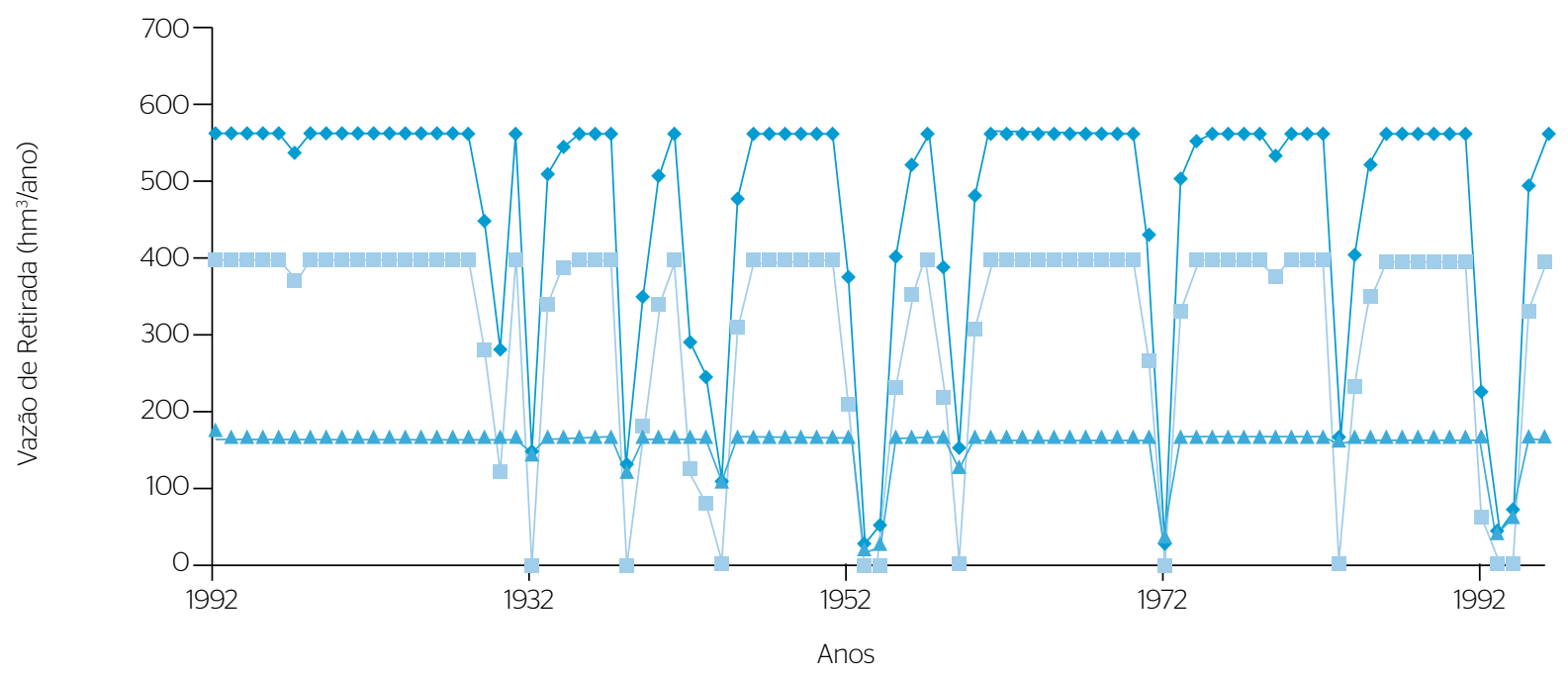

Sistema de Prioridade (Risco $=25 \%)$

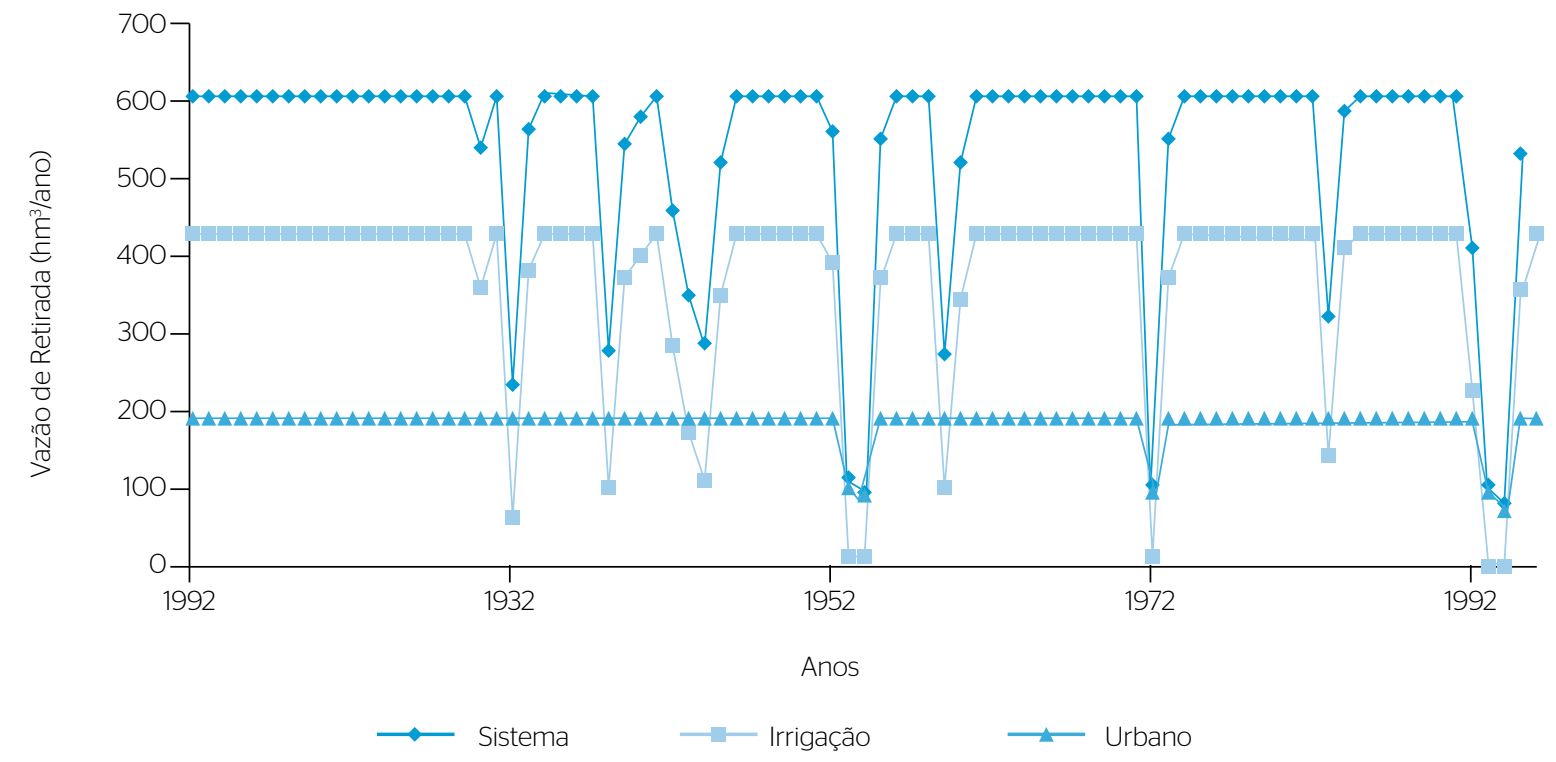

Figura 5 - Vazão alocada com o mecanismo de prioridade $\left(\mathrm{hm}^{3} . \mathrm{ano}^{-1}\right)$ no cenário de previsão de vazão com risco de $5 \%$ e $25 \%$, utilizando a série histórica de julho de 1912 a julho de 1996.

Tabela 1 - Desempenho da alocação de água para o setor urbano no sistema de prioridade considerando o modelo agregado.

\begin{tabular}{l|c|c|c} 
Critérios & $\begin{array}{c}\text { Vazão } \\
\text { zero }\end{array}$ & $\begin{array}{c}\text { Previsão de vazão } \\
\text { (Risco =5\%) }\end{array}$ & $\begin{array}{c}\text { Previsão de vazão } \\
\text { (Risco = 25\%) }\end{array}$ \\
$\begin{array}{l}\text { Rendimento } \\
\text { médio (hm³.ano-1) }\end{array}$ & 174,04 & 170,10 & 174,53 \\
\hline Garantia (volume) & 0,97 & 0,94 & 0,97 \\
\hline $\begin{array}{l}\text { Garantia } \\
\text { (frequência) }\end{array}$ & 0,88 & 0,88 & 0,94 \\
\hline
\end{tabular}

Tabela 2 - Desempenho da alocação de água para o setor de irrigação no sistema de prioridade, considerando o modelo agregado.

\begin{tabular}{l|c|c|c} 
Critérios & $\begin{array}{c}\text { Vazão } \\
\text { zero }\end{array}$ & $\begin{array}{c}\text { Previsão de vazão } \\
\text { (Risco =5\%) }\end{array}$ & $\begin{array}{c}\text { Previsão de vazão } \\
\text { (Risco = 25\%) }\end{array}$ \\
\hline $\begin{array}{l}\text { Rendimento } \\
\text { médio (hm³.ano') }\end{array}$ & 321,38 & 333,93 & 361,41 \\
\hline Garantia (volume) & 0,77 & 0,80 & 0,86 \\
\hline $\begin{array}{l}\text { Garantia } \\
\text { (frequência) }\end{array}$ & 0,54 & 0,60 & 0,72 \\
\hline
\end{tabular}


Tabela 3 - Benefício médio do setor de abastecimento urbano e irrigação, em milhões de reais.

\begin{tabular}{l|c|c|c|c}
\multirow{2}{*}{ Cenários } & \multicolumn{2}{|c}{ Rateio Linear } & \multicolumn{2}{c}{ Sistema de prioridade } \\
\cline { 2 - 5 } & Abastecimento urbano & Irrigação & Abastecimento urbano & Irrigação \\
\hline Vazão zero & 17,27 & 9,29 & 19,56 & 8,22 \\
\hline Previsão de vazão (Risco = 5\%) & 17,33 & 9,06 & 18,93 & 8,36 \\
\hline Previsão de Vazão (Risco = 25\%) & 18,15 & 9,22 & 19,52 & 8,73 \\
\hline
\end{tabular}

Tabela 4 - Transferência média de risco entre a irrigação e o abastecimento urbano.

\begin{tabular}{l|c|c|c|c}
\multirow{2}{*}{ Cenários } & \multicolumn{2}{|c|}{ Benefícios (milhões de reais) } & \multicolumn{2}{c}{ Transferência de risco } \\
\cline { 2 - 5 } & Irrigação & Urbano & Monetária (milhões de reais) & Volumétrica (hm ${ }^{3}$.ano') \\
\hline Vazão zero & $-1,06$ & 2,30 & 3,36 & 25,42 \\
\hline Previsão de vazão (Risco = 5\%) & $-0,70$ & 1,59 & 2,29 & 18,89 \\
\hline Previsão de vazão (Risco = 25\%) & $-0,48$ & 1,37 & 1,85 & 13,75 \\
\hline
\end{tabular}

Além disso, o setor de irrigação, de menor prioridade no abastecimento de água do Estado do Ceará, planeja a instalação de sua produção com base na garantia hídrica dada pelo Governo $\left(Q_{90}\right.$ para sistema analisado) e, como atividade que precisa de água para sua execução, a redução dessa garantia pode ocasionar a desestruturação do processo produtivo e do modo de vida das famílias que são dependentes da existência e uso desse para alcançar o desenvolvimento social e econômico.

Para Francalanza et al. (2013), é importante observar que, muitas vezes, as políticas públicas relacionadas à água priorizam determinados usos que se relacionam com a geração de valor pelo sistema capitalista, sem interface com os problemas distributivos do recurso que dizem respeito aos usuários com pouca capacidade de pagamento. Com isso, faz-se necessário o desenvolvimento de políticas públicas ou de instrumentos que promovam uma boa governança da água e reduzam as disparidades e os conflitos entre os usos.

A avaliação da alocação em sistemas de transferência hídrica também nos revela que os conflitos pelo uso da água surgem não simplesmente pela limitação da disponibilidade de água, mas porque a sociedade é marcada por dicotomias em que o uso dos bens, seja natural ou não, nem sempre são disponibilizados a todos da mesma forma.

Os conflitos gerados pela transferência hídrica significam, no caso deste estudo, uma forma de dominação e disputa referente ao desenvolvimento do território, sendo esse não apenas uma porção de terra, mas, sim, uma categoria que é gerada a partir do espaço que, segundo
Raffestin (1980), apresenta-se como resultado da ação de um ou mais atores que se apropriam concretamente ou abstratamente de um espaço. Assim, refletir sobre esses conflitos requer perceber a heterogeneidade física do espaço e a diversidade econômica, cultural e social dos usuários de água, bem como as vulnerabilidades que eles estão expostos e as condições de uso do recurso hídrico.

Compreender o processo que desencadeia conflitos relativos ao uso da água na contemporaneidade remete à construção de uma institucionalidade hídrica e à produção de normas e leis que compõem os arranjos institucionais e o arcabouço legal que dão o tom da gestão das águas. Desse modo, os riscos existentes na alocação de água entre os setores e a consequente iniquidade do sistema apontam a necessidade da gestão desse recurso ser pautada no tripé: oferta, demanda e conflitos.

\section{CONCLUSÃO}

O estudo avaliou os riscos da alocação de água entre usos que se localizam em bacias hidrográficas distintas e que possuem interesses conflitantes. A alocação de água foi realizada por dois métodos de rateio da disponibilidade hídrica: rateio linear (método base) e sistema de prioridades. A imposição do sistema prioritário elevou a garantia volumétrica do setor urbano em 0,14 e reduziu a garantia da irrigação em 0,08 no cenário de vazão afluente zero. Essas diferenças de garantias refletem nos benefícios obtidos pelos setores em que, neste estudo, a irrigação perdeu $\mathrm{R} \$ 1,06$ milhões e o abastecimento urbano ganhou $\mathrm{R} \$ 2,30$ milhões. 
O sistema de prioridade revelou que as infraestruturas de transferência hídricas proporcionam ganhos ao garantir a segurança hídrica para o setor prioritário, porém causam perdas quando extinguem o direito de uso da demanda de menor prioridade, indicando que a alocação de água também é um processo de distribuição de risco.

Verificou-se também que a transferência de risco, tanto volumétrica quanto monetária, pode ser minimizada com o uso da informação climática. Nesse sentido, a informação climática pode ser uma alternativa para o alcance de uma alocação de recursos hídricos eficiente e que proporcione equidade ao sistema de recursos hídricos.

Deste modo, uma alternativa para a alocação de água em ambientes com sistemas de transferência hídrica seria definir um risco aceitável com vistas a aumentar o nível atual de benefícios da irrigação e a satisfação do abastecimento urbano. Esse risco pode ser estabelecido com base em modelos de previsão climática sazonal. Além disso, faz-se necessário definir regras de alocação entre usuários de uma mesma categoria de uso.

Uma terceira alternativa é promover mudanças estruturais no atual modelo de alocação de água. Nesse caso, sugere-se a incorporação de mecanismos financeiros nesse processo, como, por exemplo, contratos entre usuários, seguros, derivativos climáticos e compensação financeira, e o melhoramento da definição da vazão máxima outorgável. Esses mecanismos são fundamentais para a eficiência e a sustentabilidade do gerenciamento de recursos hídricos.

Outro aspecto da disponibilidade de longo prazo que necessita ser melhorado é a quantificação da disponibilidade hídrica para a outorga, isto é, o volume outorgável. Recomenda-se que esse volume seja emitido com diferentes garantias de longo prazo (por exemplo, G3 = 80\%, G2 = 90\% e G1 = 99\%). Essas garantias diferenciais estariam associadas a prioridades em anos secos, obviamente, $\mathrm{P} 3<\mathrm{P} 2<\mathrm{P} 1$. Os usuários pagariam preços diferentes e crescentes com o aumento das prioridades $\operatorname{Pr} 3<\operatorname{Pr} 2<\operatorname{Pr} 1$. Um volume alocável de longo prazo seria definido para cada bacia e subsistema. Nesse caso, haveria uma associação direta entre direito de uso definido pela outorga e a cobrança pelo uso da água. Os usuários escolheriam a prioridade e a garantia de abastecimento em períodos de escassez hídrica e, consequentemente, a sua disposição em pagar pela água.

Os ajustes sugeridos possibilitam o alcance de uma maior capacidade de adaptação e robustez ao sistema de gestão de recursos hídricos, bem como um nível mais elevado de sustentabilidade social, econômica e ambiental.

\section{REFERÊNCIAS}

BANCO MUNDIAL. (2005) Transferência de água entre bacias hidrográficas. Brasília. 93p.

CEARÁ. (2010) Lei no 14.844 de 28 de dezembro de 2010. Dispõe sobre a política estadual de recursos hídricos, institui o Sistema Integrado de Gestão de Recursos Hídricos - SIGERH, e dá outras providências.

COGERH. (2010) Revisão do Plano de Bacias Hidrográficas das Bacias Metropolitanas: RT 2. Fortaleza: Yibi, COGERH, 196p.

GONG, G.; WANG, L.; CONDON, L.; SHEARMAN, A.; LALL, U. (2O1O) Simple framework for incorporating seasonal streamflow forecasts into existing water resource management practices. Journal of the American Water Resources Association, v. 46, n. 3, p. 574-585.

GUIHAN, R.; POLEBITSKI, A.; PALMER, R.; BROWN, C. (2O13) Integrating Climate Forecasts and Reforecast Products into Reservoir Operations Management. In: World Environmental and Water Resources Congress, Showcasing the Future, Asce, p. 1574-1580.

FAO. (2004) Economics of water allocation. In: Economic Valuation of water resources in agriculture, FAO Water Report 27. TURNER, K.; GEORGIOU, S.; CLARK, R.; BROUVER, R., (org). Food and Agriculture Organization of the United Nations, Rome.
FRANCALANZA, A.P.; JACOB, A.M.; EÇA. R.F. (2013) Justiça ambiental e práticas de governança da água: (re) introduzindo questões de igualdade na agenda. Ambiente e Sociedade, v. 16, n. 1, p. 19-38.

HARVEY, D. (2014) A condição pós-moderna. São Paulo: Edições Loyola Jesuítas.

LAYRARGUES,P.P.(1997)Doecodesenvolvimentoao desenvolvimento sustentável: Evolução de um conceito?. Proposta, v. 25, n. 71, p. 5-10.

MACHADO, B.G.F. (2009) Análise econômica aplicada à decisão sobre alocação de água entre os usos irrigação e produção de energia elétrica: o caso da Bacia do rio Preto. 2009. 160 f. Dissertação (Mestrado), Universidade de Brasília, Departamento de Engenharia Civil e Ambiental.

NASCIMENTO, E.P. (2012) Trajetória da sustentabilidade: do ambiental ao social, do social ao econômico. Estudos Avançados, v. 26, n. 74 , p. $51-74$

RAFFESTIN, C. (1980) Pour une géographic du pouvoir. Paris: Litec. 250p.

ROA-GARCÍA, M.C. (2014) Equity, efficiency and sustainability in water allocation in the Andes: Trade-offs in a full world. Water Alternatives, v. 7. n. 2, p. 298-319. 
ROBERTSON, A.W.; BAETHGEN, W.; BLOCK, P.; LALL, U.; SANKARASUBRAMANIAN, A.; SOUZA FILHO, F.A.; VERBIST, K.M.J. (2014) Climate risk management for water in semi-arid regions. Earth Perspectives, p. 1-12.

SILVA, S.M.O.; SOUZA FILHO, F.A.; AQUINO, S.H.S. (2015) Alocação de custos e a cobrança pelo uso da água no Estado do Ceará. REGA, v. 12, n. 2, p. 47-59.

SOUZA FILHO, F.A. (2005) Alocação de água sazonal e anual: modelos matemáticos, experimentação comportamental e justiça alocativa. 2005. 439 f. Tese (Doutorado), Escola Politécnica da Universidade de São Paulo, Universidade de São Paulo.
SOUZA FILHO, F.A.; BROWN, C.M. (2009) Performance of water policy reforms under scarcity conditions: a case study in Northeast Brazil. Water Policy, v. 11, p. 553-568.

SOUZA FILHO, F.A.; LALL, U. (2003) Seasonal to interanual ensemble streamflow forecasts for Ceara, Brazil: Applications of a multivariate, semiparametric algorithm. Water Resources Research, v. 39, W1307.

SOUZA FILHO, F.A.; LALL, U. (2004) Modelo de previsão de vazões sazonais e interanuais. Revista Brasileira de Recursos Hídricos, v. 9, n. 2, p. 61-74.

SPEED, LI Y. R; T. LE QUESNE, G.P.; ZHIWEI, Z. (2013) Basin Water Allocation Planning. Principles, procedures and approaches for basin allocation planning. UNESCO, Paris. 143p. 